\title{
A MEDICALIZAÇÃO DO COTIDIANO COMO SUPRESSÃO DA INICIATIVA
}

\section{THE MEDICALIZATION OF EVERYDAY LIFE AS A DELETION OF THE INITIATIVE}

Nilton de Júlio de Faria ${ }^{1}$ Felipe Eduardo de Carvalho Ferreira ${ }^{2}$ Júlia Pouzas Straessli Pinto ${ }^{3}$

\section{RESUMO}

A segunda metade do século vinte foi marcada com grandes transformações, dentre elas o avanço de tecnologias em diferentes esferas da cultura. Tal avanço, pautado na velha proposição do positivismo: "conhecer para predizer e controlar", gerou uma falsa sensação de controle sobre o mundo e sobre o indivíduo. No que concerne à saúde, é possível identificar a implementação de equipamentos diagnósticos cada vez mais precisos, sugerindo, inclusive a possibilidade de diagnósticos precoces que possibilitariam intervenções médicas, também precoces que, teoricamente evitariam o surgimento de doenças. Com a saúde mental não é diferente, classificações como CID ou DSM possibilitariam o preciso diagnóstico para uma indústria farmacêutica cada vez mais envolvida em pesquisas que atendam a esta demanda. Consequentemente, a saúde passa a ser entendida como consumo, remetendo-nos à ideia de terapêutica prótese. O presente trabalho busca apresentar as diversas perspectivas sobre o processo de patologização da vida. Tendo como referência a Ontologia da Ação de Paul Ricoeur, destaca-se que para a concepção de saúde da contemporaneidade é necessário reparar esse organismo considerado exclusivamente biológico em detrimento do humano. Nesse sentido, discorremos sobre a medicalização à vida inclusos nos processos de adoecimento e saúde, possibilitando um pensamento mais crítico e recorrendo à alternativas e estratégias para um viver menos nocivo ao humano e sua existência que vem sendo patologizada e consequentemente desumanizada.

Palavras-chave: Medicalização. Patologização. Desumanização da Vida.

1 Doutor em Psicologia Social pela Pontifícia Universidade Católica de São Paulo. Campinas/SP, Brasil. E-mail:nfaria@uol.com.br

2 Psicólogo pela Pontifícia Universidade Católica de Campinas. Leme/SP, Brasil.E-mail: felipeferreiraa.ff@gmail.com

3 Psicóloga pela Pontifícia Universidade Católica de Campinas. Americana/SP, Brasil.E-mail: julia.pouzas@hotmail.com 


\section{ABSTRACT}

The second half of the twentieth century was marked with big changes, among them the advance in technology in different fields of culture. Such advances were based on the positivism: "know to predict and control", which generated a false sensation of controlling over the world and the human beings. Concerning health, it is possible to identify the implementation of diagnostic equipment even more precise, suggesting the possibility of precocious diagnostics that would enable medical interventions, also precocious, that would theoretically prevent the onset of a disease. It is not different with the mental health, classifications like ICD or DSM would provide accurate diagnosis for a pharmaceutical industry increasingly involved in research that meets this demand. Consequently, health begins to be known as consumption, referring us to the idea of a kind of prosthetic therapy. This article presents the different perspectives on the process of pathologization of life. Having as reference the Ontology of Action of Paul Ricoeur, it is noteworthy that for the contemporary conception of health it is necessary to repair the organism considered exclusively biological to the detriment of the human being. In this sense, we discuss the medicalization of life included in the processes of illness and health, enabling a more critical thinking and resorting to alternatives and strategies for a less harmful life to humans and their existence that has been pathologized and consequently dehumanized.

Keywords: Medicalization. Pathologization. Dehumanization of Life.

\section{INTRODUÇÃO}

O século vinte foi marcado por grandes transformações em diversos âmbitos da cultura. Foram transformações que perpassaram a configuração política, a economia, a arte, as crenças e a ciência. $\mathrm{O}$ homem nunca se viu frente a tantas transformações em tão pouco tempo. A velocidade com que as novidades se apresentaram ao cotidiano dos indivíduos parece surpreendê-los ao imaginar que a ciência seria capaz de apresentar soluções a cada enfrentamento que a vida colocasse.

As transformações vividas pelas tecnologias da informação permitiram transformações em âmbitos triviais da vida cotidiana; alteram-se as relações de trabalho, os meios de comunicação, os processos educacionais, dentre outros. Interessa-nos, mais de perto, as transformações vividas no campo da saúde. Em que se considere as próprias transformações pelas quais passaram as concepções de saúde. Estas alteram o estilo de vida ao menos para aqueles que tenham acesso a bens e serviços; o que se observou foi uma grande tendência em homogeneizar a vida, seus sentidos e suas produções.

É possível observar que o conceito de saúde perpassa por diversos âmbitos da sociedade, assumindo diversos significados ao longo da história. Com o termo "doença", o outro lado do binômio, também não é diferente, os dois são caracterizados 
a partir de uma época, levando em consideração aspectos sociais, políticos, culturais e econômicos. Scliar (2007) desenvolve um histórico de como a nossa cultura significa a questão da saúde, segundo o autor a humanidade tem se empenhado a enfrentar as doenças de várias formas, enxergando estas como ameaças para os seres humanos. As primeiras formas de lidar com doenças, ou comportamentos de mal-estar, estavam relacionadas a atividades mágico-religiosas, enxergando a doença como ação de forças alheias, pecado ou maldição. Com o passar dos anos foram surgindo novas formas de tratamentos diante das concepções de saúde, desde convocação de espíritos que seriam capazes de retirar o mal do corpo do doente, equilibrar os fluídos do corpo como propunha Hipócrates; medidas terapêuticas como acupuntura e ioga (buscando restaurar um fluxo normal de energia no corpo), a criação de abrigos e cuidados dos doentes pela igreja e até por meio da administração de doses de minerais e metais aos doentes (demonstrando também uma influência da química sobre o cuidar da doença).

No final do século XIX, Louis Pasteur e outros laboratórios descobriram a existência de microrganismos causadores de doenças, introduzindo aqui a criação de soros e vacinas. A partir dessa descoberta, pesquisadores passam a verificar as influencias que poderiam ser causadoras de doenças, analisando os níveis de mortalidade em diferentes bairros, o aumento da urbanização e como poderiam afetar negativamente o sujeito, as condições sanitárias, ou seja, avaliando qualquer contexto que poderia e que realmente afetavam os indivíduos que estavam inseridos neles (Scliar, 2007). Assim, passa a ser implementada, em alguns países, a ideia de intervenção do estado na área de saúde pública.

Após o término da Primeira Guerra Mundial, foi criada a Liga das Nações a partir do Tratado de Versalhes, buscando um espaço para discussões entre todas as nações, evitando guerras. Mas esse objetivo só foi atingido após a Segunda Guerra Mundial, criando assim, por meio de interesses políticos e como forma de restaurar as destruições do pós-guerra, a Organização das Nações Unidas (ONU) e a Organização Mundial da Saúde (OMS).

No ano de 1948 a OMS reconhece o direito à saúde para todos e como obrigação do estado a promoção e proteção da saúde, com novas concepções de sociedade e de direitos individuais. É apresentada uma formulação de saúde como um estado de completo bem-estar físico, mental e social e não apenas da ausência de doenças ou enfermidades. Sendo assim, essa formulação tendência a compreender o indivíduo não apenas sob uma ótica orgânica, mas constituída por múltiplos fatores, como as condições sociais e individuais visando à equidade; que consequentemente não culpabiliza apenas o indivíduo para se determinar o que é saúde ou doença. Mas ainda assim é presente a ideia da saúde com um fundo de objetivação, pois assim como ao longo da história, quando se fala em saúde, têm-se em mente a eliminação da doença por meio de uma homogeneização, que possivelmente pode afastar o sujeito do seu contato com seus significados íntimos atribuídos à sua forma de vida e seu próprio modo de ser; que primeiro é chamado de "doença" para depois ser removida da vida do sujeito para se atingir o que se tem como "bem-estar", ou saúde.

No final da década 1960, foi forjado o termo medicalização, referindo-se a crescente apropriação dos modos de vida do homem pela medicina, o termo pressupunha a tomada 
de aspectos corriqueiros da própria vida como algo passível de controle médico. Segundo Silva, Schäfer e Bonfiglio (2013), este termo surgiu como uma crítica negativa ao excesso de medicalização, denunciando a influência em campos que não seriam médicos ou patológicos, mas da própria vida.

A literatura indica que a medicalização surge quando um problema rotineiro passa a ser definido a partir de termos médicos: descrito por uma linguagem própria, compreendido e tratado por meio de uma racionalidade exclusiva. A medicalização apresenta formas de cuidado e de se viver aos sujeitos, ensinando-os e dando-lhe maneiras e recursos para lidar com a vida cotidiana, com o fim de torná-los "normais". Como consequência desse processo assistiu-se a retirada da autonomia dos indivíduos, sua capacidade de pensar e de se autocuidar, uma vez que essa função é atribuída a outros agentes, transformando modos de existência em doenças e, portanto, em questões médicas, que por sua vez necessitam de intervenções colocando a pessoa como insuficiente para lidar com isso de maneira independente. Um exemplo disso é quando Christofari, Freitas e Baptista (2015) apontam que é possível compreender a medicalização como um dispositivo que transforma problemas políticos, sociais e culturais em questões pessoais e que podem ser classificadas e tratadas. Transformar questões culturais em problemas médicos implica não considerar a doença como algo para além do indivíduo; culpabilizando a vítima pelo seu modo de ser e não levando em consideração quaisquer outros fatores.

Destaca-se, ainda, a ótica biologizante e determinista, em que segue tratando os aspectos da vida como determinados por estruturas que não interagem com o ambiente, retirando do cenário os processos e fenômenos característicos da vida em sociedade, como a historicidade, a cultura e a organização social com suas desigualdades, como propõe Moysés e Collares (2013). Nessa perspectiva é possível afirmar que a medicalização acaba isolando o sujeito de seu contexto, com um olhar para apenas alguns fragmentos dos modos de existir, tornando-os patológicos, como dito por Christofari et al. (2015). O próprio fazer da saúde que se dá na sociedade se apropria dessa concepção, atribuindo-se a competência para legislar e normatizar o que seja saúde ou doença. Inclusive, os próprios diagnósticos na área da saúde e avaliações dos sujeitos no contexto da educação e do trabalho são analisados a partir dessa base, tornando o sofrimento e "anormalidades" como desvios, e muitas vezes como exclusivos de desordens fisiológicas, como dito por Guarindo (2007). Abre-se caminhos para a tratamentos medicalizantes que passam a ser recursos para quaisquer desvios do humano, determinados por essa visão biologizante. Segundo Zanella, Luz, Benetti e Roberti Junior (2016), a medicalização da vida, é entendida, como um processo ativo de tornar passíveis de diagnóstico, tratamento e prevenção de alguns eventos e condições até então considerados pertinentes e próprios da existência humana. Não restringindo isso apenas à medicina, mas a quaisquer intervenções desse gênero (inclusive as possíveis psicologizações da vida), que retiram do sujeito sua capacidade de autonomia e suas possibilidades de ação diante do que se coloca como "patológico".

É inegável os avanços tecnológicos da medicina e da indústria farmacêutica, e como estas buscam amenizar o sofrimento, seja na dimensão física ou mental, mas junto à isso há uma tendência de se evidenciar as patologias e psicopatologias como 
produtos de alterações fisiológicas e/ou anatômicas, aumentando e validando o uso de tratamentos como os psicofármacos e medicamentos em geral que, consequentemente, enaltecem o reducionismo biológico, a supervalorização de processos químicos e a patologização de características subjetivas (Soalheiro e Mota, 2014). Mas pensar em medicalização, é ir além do uso de medicamentos, é pensar na condição humana a partir dos referenciais da medicina, sendo a medicação parte do processo da medicalização que também partem dessa perspectiva; com uma lógica reducionista, patologizando formas de ser e enaltecendo a necessidade de repará-las. Com isso, torna-se importante também considerar essa não atenção ao uso indiscriminado desses medicamentos, possivelmente libertando indivíduos desse cenário e evitando que surtem efeitos negativos, fisiológicos, ou psicológicos e sociais, como o estigma e a segregação, afetando a subjetividade e todos os outros efeitos que iremos discutir ao longo desse texto (Zanella et al., 2016).

O presente ensaio busca desenvolver algumas reflexões acerca do que se considera a medicalização da vida. Inicialmente serão apresentadas algumas publicações atuais que tratam especificamente do tema "medicalização" ou "patologização" da vida. Não se trata de uma pesquisa bibliográfica, nem tampouco uma revisão bibliográfica, recorrermos a estas publicações tão somente para sedimentar nossas reflexões. A Ontologia da Ação de Paul Ricoeur será nossa referência para a compreensão dos agentes envolvidos nesse processo.

\section{A DESUMANIZAÇÃO DA VIDA}

Falar de medicalização, segundo aponta Soalheiro e Mota (2014), requer uma difícil tarefa; a de demarcar o que se entende por normal e patológico no campo da produção do saber científico, tal tarefa faz-se ainda mais complexa quando envolve a compreensão das experiências de sofrimento e adoecimento psíquico, muitas vezes refratário aos enquadres e classificações como ocorre com as chamadas "doenças do corpo". Michel Foucault (1988) ao discutir a psicologia do século dezenove, traça uma longa discussão apontando para o fato de que os modos de produção de conhecimento sobre as doenças físicas foram os mesmos que os utilizados para os da doença mental, considerando que as doenças do corpo tinham um caráter nosográfico e naturalizante, é compreensível que a produção dos saberes à época centrava-se mais nos sintomas do que no sujeito que os vivia.

A medicalização da vida, como a vivemos hoje, ainda naturaliza supostos transtornos, julgando-os como males contemporâneos e ainda privilegiando os sintomas. Soalheiro e Mota (2014), são enfáticos ao afirmar que a medicalização torna transtornos, tais como o déficit de atenção, a depressão, a bipolaridade, dentre outros, em sintomas comuns e que podem ser combatidos com o uso de medicamentos e intervenções médicas, indicando o cuidado do sintoma e não da pessoa (Faria, 2017)

Há uma concepção de normalidade extremamente restrita em que, segundo Lalande (1938), o normal seria aquele que não se inclina nem para a esquerda nem para a direita, portanto é aquele que se conserva em um justo meio-termo, diante de um padrão que foi estabelecido. Como se vê, tem-se como normal, aquilo que é entendido como "deve ser", aquele 
que se encontra como maioria de uma espécie ou aquele que constitui a média. Segundo Horwitz e Wakefield (2009), a medicalização tornar-se cada vez mais naturalizada, tornando emoções, modos de agir e questões pertinentes à própria vida, como sintomas patologizantes. Como um meio para viabilizar isso, há uma numerosa quantidade de transtornos mentais descritos nos Manuais de Diagnóstico, fazendo com que seja muito difícil um indivíduo não se enquadrar em um diagnóstico em algum momento de sua vida. Nesse pensamento, qualquer sintoma que está fora da norma estabelecida pela sociedade pode ser considerado patológico, negando assim o caráter individual do sofrimento humano e tratando-o como mera abstração (Zanella et al., 2016).

Quando se fala em cuidado e na promoção de saúde, há um dilema ético envolvido em que cuidar do outro seria olhar para os referenciais de saúde e doença presentes na cultura, estabelecendo modos de ser que o sujeito deve atingir. Deixando de lado as necessidades que se integram na totalidade da existência do indivíduo. Diante desse cenário, a "normalização" e a "normatização", tende a responder então, às demandas morais de acordo com um modo de vida e, que, portanto, são construídos pela cultura. Soalheiro e Mota (2014) inclusive, dizem que a medicalização segue uma lógica contraria da saúde e da ética responsável, pois subverte o papel do profissional e afeta as subjetividades dos indivíduos, com uma cultura produtora de subjetividades medicalizadas. Com isso, é possível pensar que nos dias atuais toda a forma de sofrimento e mal estar deve ser evitada e/ou remediada, negando o caráter humano do sofrimento e eliminando qualquer tipo de mal estar, buscando "normalizar" o indivíduo.

Ao buscar reparar "anormalidades", o sujeito se submete a tratamentos e medicamentos criados pela indústria farmacêutica, que apresentam, de forma ilusória, maneiras reparadoras de "irregularidades" do humano. Prometendo a cura, eficácia e rapidez do tratamento e reduzindo os indivíduos a seres cada vez menos humanos e mais desejantes de um comportamento padronizado e supostamente normal.

Referindo a medicalização como reparadora de anormalidades, há um crescente número de pessoas que se descobre como anormal em relação a alguma norma desejável e consequentemente como pacientes que podem ser submetidos a uma terapêutica. Do ponto de vista de Tabet, Martins, Romano, Sá e Garrafa (2017), como resultado deste pensamento, há a construção de uma sociedade mórbida, que naturaliza o uso de medicamentos e das instituições médicas que atestam uma morbidade universal. Seguindo essa mesma lógica, como dizem Brzozowski e Caponi (2013), a medicalização é aplicada em aspectos naturais da vida, como a sexualidade, o nascimento, a menopausa, o envelhecimento e até o processo de morrer; considerados então, como desvios de comportamentos.

Ainda segundo Brzozowski e Caponi (2013), os desvios de comportamento podem ser vistos como fenômenos universais que foram ditados através de normas sociais, determinadas por certos grupos que criam regras e impõem suas definições para outros grupos, por meio do julgamento e da aprovação social. São estas normas que definem quais são os comportamentos normais e "anormais". Com isso, muitos desses desvios e sintomas são taxados como transtornos, quando se leva em consideração um modo normativo de ser, consequentemente trazendo condutas medicalizadas para atingir a concepção de saúde desejável da sociedade. 
Para os autores, este comportamento pode ser evidenciado pela tendência de se procurar as causas e as soluções de problemas dentro do próprio indivíduo, desconsiderando o meio em que este está inserido.

Como uma tentativa de aproximação, podemos considerar que essa tendência de classificar e normalizar o humano, próprio da medicalização, segundo a ontologia da ação de Paul Ricoeur, poderia ser entendida como algo que desconsidera a constituição do sujeito a partir da dialética da ipseidade (aquilo que diferencia um ser do outro) e da alteridade (relação de contraste na experiência com o outro e o mundo). Ricoeur aponta a dialética da ipseidade e da alteridade como modo do sujeito vir a ser si mesmo, ele a considera como constituintes da subjetividade, por meio da articulação do si, do outro e do social, mediante as relações de contraste e de diferenciação com o outro que serão essenciais para a construção de uma identidade pessoal (Ricoeur, 1998). A concepção de pessoa posta por Ricoeur remete a uma compreensão do sujeito dotado de uma consciência ampliada e descentralizada, tendo em vista que, imerso no mundo, é que nos constituímos. Uma concepção apenas biologizante fragmenta a experiência humana e sua constituição como pessoa, possibilitando, assim, uma padronização que orienta as práticas da medicalização.

A medicalização então, deixa de compreender o homem na sua totalidade, extraindo-o do seu contexto social e sua historicidade que são constituintes da subjetividade. Ele passa a ser classificado estabelecendo quem ele é e direcionado como ele deve ser diante dos critérios de normalidade presentes nessa perspectiva biologizante. Assim, a experiência do indivíduo com o outro, o mundo e sua subjetividade é limitada, levando-o para uma desumanização do seu próprio modo de existir. Compreender o humano a partir de uma explicação orgânica e descontextualizada é compreendê-lo não como humano, mas sim como um sistema que tem um funcionamento a partir de uma dualidade entre saúde e doença, desconsiderando quaisquer significados subjetivos.

\section{A CULTURA MEDICALIZADA E A SAÚDE COMO CONSUMO}

É muito presente na sociedade uma exigência de bem-estar constante, não havendo espaço nem tempo para a dor, sendo todas as adversidades inerentes à existência decididamente evitadas e que devem ser reparadas. A contemporaneidade estaria então, aderida a um pensamento quase absoluto no discurso técnico, anestesiando-se com substâncias que prometem muito, desde a perda de peso até a felicidade plena. Neste contexto, a medicalização assume um sentido de poder ilimitado da ciência, em que se pode ser produzida a medicalização da e na sociedade, uma vez que comportamentos e acontecimentos da vida cotidiana se tornam passíveis de tratamento, cura, prevenção e controle. Uma visão ilusória em que a doença e a necessidade de medicalizar são permanentemente fabricadas (Soalheiro e Mota, 2014).

Sob essa ótica, temos uma visão cultural da saúde como consumo. Para Illich (1975), uma estrutura social e política se apresenta com um poder de cobrir as pessoas com terapias que elas foram ensinadas a desejar, já que se tem como necessário o reparo de qualquer “irregularidade” 
ou "desvio" do funcionamento humano. Entretanto, o ritual médico transformou a dor em uma sequência de obstáculos que ameaçam o bem-estar desejável, obrigando o indivíduo a recorrer incessantemente a consumos produzidos e monopolizados pela instituição médica, assumindo também a gestão da fragilidade do indivíduo. Simultaneamente, o consumidor de cuidados da medicina torna-se impotente para lidar com seu "mal funcionamento" e de seus semelhantes, restringindo a possibilidade de interpretação e de reação autônoma da pessoa, já que ele fica a mercê da instituição médica para seu cuidado (Illich, 1975). Como complemento disso, há outra ideia, em que Tesser (2006) diz que sem matriz cultural ou conhecimento que propiciem outra saída, as pessoas aprendem a conceber sua própria dor ou adoecimento como fato clínico objetivo, que pode ser submetido a um tratamento. Desenvolvendo assim, um processo cíclico em que o indivíduo aprende a se ver como consumidor de tratamentos.

A saúde como consumo ainda traz outra diretriz além do domínio profissional sobre a pessoa, com uma ideia de autocuidado, mas que não deixa de ser medicalizante. Nela, não há necessariamente o controle profissional, mas permite à pessoa acesso a recursos e formas estipuladas de ser, que driblam o que é considerado como ameaça à saúde. Um exemplo disso seriam as medicinas alternativas, as diversas correntes da autoajuda, as modas dietéticas, as variadas práticas de corpo e etc. Inclusive, Tabet et al. (2017) afirma que a medicina institucionalizada dentro da saúde diminui à medida que essas formas de autocuidado passam a influenciar mais o leigo no que diz respeito à saúde. Logo, essa suposta desmedicalização da saúde também se dá em um processo iatrogênico, pois ao invés do ganho de autonomia do sujeito no manejo consciente dos meios para garantir sua saúde, é instituída uma pseudoautonomia iatrogênica, por meio de um autocuidado que também seria medicalizante (Tabet et al., 2017).

A própria ideia de cura com terapias e medicamentos, seja de autocuidado ou não, trazem uma visão de que são capazes de devolver ao paciente alegria, tranquilidade e capacidade produtiva de forma rápida e eficaz. Evidenciando mais uma vez a ilusão de que é possível normalizar quaisquer tipos de comportamentos taxados como "anormais". Com essa busca incessante pela normalidade, os pacientes são impulsionados e impulsionam os próprios médicos a prescrição de medicamentos, trazendo como consequência a generalização de seu uso, além da popularização dos diagnósticos, que com facilidade, convertem características humanas em patologias, como dito por Silva et al. (2013).

Para Tesser (2006) a ideia de progresso em nossa civilização, torna-se sinônimo de redução de sofrimento mediante a tentativa de eliminação ou sedação de dores, sintomas e controle dos riscos e doenças. No entanto, a medicalização, controla qualquer possibilidade do indivíduo de lidar com os sofrimentos e perdas decorrentes da própria vida, por transformar as dores da existência em doenças passíveis de controle, como dito por Illich (1975). Illich inclusive, traz uma crítica à essa visão de homem em termos de mecânica, em que o sujeito passa a ser visto de maneira semelhante a uma máquina que pode ser reparada por um engenheiro. Que é o que o autor chama de iatrogênese estrutural. Em que a medicalização retira o sofrimento e seu significado íntimo e pessoal, e transforma a dor em problema técnico. Então a dor, a doença e seus riscos começam a ser vistos primeiro como a condição dos homens 
a quem a corporação médica não concedeu o benefício de sua caixa de ferramentas, fazendo com que a dor e sua eliminação adquiriram lugar central na angústia do nosso tempo.

\section{APENAS HUMANO}

Diante do que já foi discutido, podemos dizer então que o homem moderno considera a dor exclusivamente como um incômodo e que como todo estado desagradável, deve ser evitado. Assim como Melo, Ribeiro e Moreira (2015) apontam quando dizem que o sofrimento na contemporaneidade é uma experiência associada à patologia e entendida como essencialmente negativa, que como tal, deve ser combatida por ser uma resposta que não é natural nem inerente ao ser humano. E como um desdobramento disso, temos essa patologização do sofrimento, em que cada vez mais pessoas estão sendo diagnosticadas e tratadas de forma medicamentosa e por outras terapêuticas.

Ricoeur (1992) diz que a questão do sofrimento e da dor reveste-se de uma dimensão ética e filosófica a partir do momento em que se encontram no mesmo afeto, a passividade do sofrer, até mesmo quando infligido pelo outro. Esse sentimento relacionado ao sofrimento pode ser encontrado exacerbado pelos efeitos da violência sofrida, quer esta seja física ou simbólica, real ou fantasiada, em que a pessoa se sente vítima de algo e não se vê como agente, exigindo ainda sentido disso (Ricoeur, 1998). Dessa forma, é incorporado um nível de passividade e perda de controle, e o sofrimento é visto como algo mal, algo em excesso, que é sofrer demasiadamente e sem sentido.

Esse pensamento ganha sentido, quando a pessoa é colocada apenas como vítima do sofrimento, que é algo inserido na própria cultura da medicalização. Pois quando se coloca a dor como algo externo ao sujeito, é como se aquilo que lhe faz sofrer não fizesse parte de sua vida e de todo seu contexto, muito menos colocando a pessoa como responsável pelo o que Ihe acontece e como autônoma para lidar com isso. O sofrimento então segue sendo tratado como uma eventualidade da vida, totalmente desconexa do modo de ser do indivíduo, em que o esforço para ser e perseverar nas adversidades da vida não são necessários, já que o responsável e o agente da ação não é o próprio sujeito.

A compreensão de Ricoeur acerca do sofrimento ganha significativa abrangência ao considerar as dimensões culturais presentes em nosso cotidiano que, por vezes, suprimem nossa iniciativa, o que para o autor, em sua ontologia da ação, seria a própria negação da pessoa, diz ele: "O sofrimento não é unicamente definido pela dor física nem mesmo pela mental, mas pela diminuição até a destruição da capacidade de agir, do poder fazer, sentidos como um golpe à integridade do si” (Ricoeur 1991, p. 223).

Isto posto, compreendemos que as ações de saúde que visem a homogeneização dos fazeres em nome de um dado substrato de vida saudável, acabam mais por gerar sofrimentos do que cuidar.

Para Svandra (2012), a dor de fato, muitas vezes pode aparecer realmente como sem sentido; como se isolasse os doentes e acrescentasse apenas infortúnio ao infortúnio. Mas que significado seria o desaparecimento total do sofrimento? Uma vida sem sofrimento ainda seria 
humana? Não é ela que me dá a coragem de me comprometer com o outro, para este sujeito que, como eu, pode suportá-la? E não seria o sofrimento uma condição da existência humana? Não é o sofrimento que nos proporciona novas formas de ser e saberes sobre nós mesmos?

Buytendijk (2018) diz que a experiência com o sofrimento é muito necessária, trazendo consigo uma reflexão sobre o fenômeno da dor. Pois a própria dor, por si só, provoca o questionamento do que precisa ser feito pelo sujeito, o que possivelmente pode gerar mudanças significativas. Viktor Frankl (1946), autor da logoterapia e que traz alguns desdobramentos sobre o sentido do sofrimento em suas obras, também diz que: "quando não somos capazes de mudar a situação, somos desafiados a mudar nós mesmos” (p. 137); sendo o sofrimento algo que nos impulsiona possivelmente para alguma direção.

Com as afirmações dos autores, podemos dizer então que o sofrimento é algo que nos permite buscar novas formas de ser no mundo, pois uma vez que o sofrimento se torna presente, ele permite uma reconfiguração do sujeito para que ele possa lidar melhor com o que lhe é apresentado, ou até com situações futuras. Mas, além disso, pode ser também uma chance de envolvimento mais íntimo do "doente" consigo mesmo, seu meio e sua vida. Tal envolvimento pode ser terapêutico; dele pode a pessoa sair mais forte, mais autônoma, mais responsável por si mesma e perante a vida e o sofrimento dos outros. Segundo Frankl (1946), mesmo uma pessoa desamparada, numa situação sem esperança, enfrentando algo que não pode mudar, ergue-se a si mesma, crescendo para além de si, mudando-se. Possivelmente transformando até a tragédia pessoal em triunfo.

Dessa forma, a doença não deve ser entendida apenas como o desequilíbrio ou a desarmonia do corpo, é também o esforço que a natureza exerce no homem, para que o mesmo possa obter um novo equilíbrio, como diz Canguilhem (2009). Patologizar o humano, seria então, uma forma de negar ao sujeito parte integrante da sua própria vida, deixando de compreender o indivíduo na sua totalidade. Quando a experiência do sujeito é reduzida à uma explicação biológica, todo o contexto e significados acabam sendo omitidos, e tudo o que excede o funcionamento próprio dessa visão orgânica, é visto como problema e algo de teor negativo para a vida. A medicalização pode ser compreendida então como uma vontade e iniciativa humana, de eliminar algo próprio do humano, mas que é mal compreendido por conta de uma visão de homem simplória e insuficiente diante de toda sua complexidade, sem um olhar para a totalidade e a subjetividade, ou seja, sem uma compreensão ampla e complexa do humano.

Uma possível compreensão que atenderia os desdobramentos da complexidade humana nesse sentido, seria a de Merleau-Ponty (1945/2011), por exemplo, quando ele diz que o homem é o que constitui e é constituído pelo mundo por múltiplos contornos, só sendo possível compreendê-lo a partir de uma visão que busque apreendê-lo na sua pluralidade de sentidos e significados da sua relação com o mundo (Melo et al., 2015). Dessa forma, se compreende o sofrimento não como uma experiência isolada no presente do indivíduo, mas como uma experiência multifacetada, que se constitui em um contexto histórico, social, cultural, a partir de uma situação e é vivido por cada indivíduo que tem um papel ativo na sua experiência (Melo et al., 2015). 
Para Frankl (1946) também, o verdadeiro sentido deve ser descoberto no mundo e não dentro da pessoa e de sua psiquê, como se fosse um sistema fechado. Considerando ainda que o sentido do sofrimento difere de pessoa para pessoa, de um dia para o outro, de uma hora para outra. Então o que importa é o sentido específico em dado momento na sua relação com o mundo. Mas, além disso, o sentido não pode ser compreendido a priori, pois como o autor mesmo diz, ao assistir um filme, não podemos compreendê-lo na sua totalidade sem tê-lo visto por completo, sendo assim, o sofrimento só ganha sentido a posteriori. Talvez por isso também, o sofrimento acaba sendo visto como algo ruim e um excesso à vida, pois a princípio ele se apresenta com uma experiência sensível de teor negativo; e na concepção de saúde, tudo que é ruim deve ser evitado. Mas ao longo do convívio e o contato com a dor, nos é permitido encontrar novas formas de ser no mundo jamais imagináveis.

No entanto, para se superar o paradigma da medicalização é necessário então, compreender o sofrimento e a dor diante de seu significado íntimo, e não pela visão imposta pela cultura da medicalização. Além disso, compreender que as experiências de saúde e doenças e os seus significados, integram-se na totalização da existência, isto é, na relação viva e dinâmica entre o ser e o seu mundo, suportada também pela práxis individual, como afirma Teixeira (2008). Nesse sentido, o homem não poderia ser compreendido retirando-o do mundo e da sua interação com ele, pois estão intrinsecamente ligados, e é isso que permite que ele se perceba e interaja com o meio. Melo et al. (2015) ainda afirmam, que o homem se distingue dos demais animais justamente por não ser somente um corpo físico, mas um ser também dotado de fatores psicológicos que permitem que ele tenha consciência da sua ligação com o mundo, contrariando à dicotomização de mente e corpo e o reducionismo biológico próprio da medicalização.

Mas sem uma melhor compreensão do problema da dor, do adoecimento e sem considerar o contexto sociocultural em que ocorre, a vítima perturbada e desnorteada pela dor se encontra sem outros recursos senão entregar-se ao tratamento medicalizante. Pois a medicalização coloca o homem como dependente do trato médico, deixando de lado à compreensão pessoal do doente, desagregando as relações entrelaçadoras do homem com sua doença, seus significados, seu meio e o que está próximo a ele (Tesser, 2006). Para enfrentar esse paradigma, Illich (1975), por exemplo, considera que o sujeito deve exceder a necessidade de intervenção profissional para os cuidados em saúde e agir contra o consumo intensivo da medicina moderna, não perdendo, assim, sua autonomia. Sendo essa, uma estratégia em que o indivíduo assume um papel ativo na sua própria vida, podendo reconhecer em si as próprias experiências por meio da dialética da ipseidade e alteridade, restaurando sua autonomia e independência para lidar com a dor, numa forma mais subjetiva e sem intervenções medicalizantes que, por si só, reduziriam a experiência humana. 


\section{CONSIDERAÇÕES FINAIS}

As noções de saúde construídas ao longo da história da medicina moderna perpassaram diferentes concepções de pessoa e de conhecimento, desde o filosófico até o científico, este último sempre foi pautado no binômio saúde/doença, estabelecendo normas ao dizer como deve ou não ser uma vida saudável. É sob essa perspectiva que se constituiu uma cultura da medicalização que tem se tornado cada vez mais presente na vida cotidiana, ela pode ser observada desde os comerciais divulgados em diferentes mídias, até as relações interpessoais de intimidade ou de caráter anônimo; isto é o saber médico transforma-se em senso comum, é banalizado, e passa a ser utilizado como uma forma de justificar as ações dos indivíduos, justificativa construída sob uma visão determinista e biologizante. Como resultado, assistimos a patologização da vida ocorrendo em vários aspectos da vida social, seja no sistema de saúde, no educacional e porque não, nas artes, nos esportes e outras dimensões da existência humana.

Ao se dar primazia ao biológico, o contexto social, a historicidade e as dimensões subjetivas passam a ser desconsideradas como constituinte da pessoa e ela passa a ser compreendida apenas como um sistema, o qual, pode apresentar um bom ou mal funcionamento dentro dos critérios de normalidade estabelecidos por essa visão.

O sintoma passar a ser entendido como passível de controle por meio de terapêuticas ou outras intervenções com o objetivo de eliminar quaisquer desvios que apresentem um mau funcionamento, sempre com vista a uma homogeneização do modo de existir. Isto posto, a pessoa perde parte da sua capacidade autônoma de experienciar e de ser responsável pelas suas formas de expressão.

O sofrimento na contemporaneidade contrapõe-se ao imaginário de que todo estado desagradável deve ser evitado; isto não ocorrendo, ele passa a ser entendido como uma patologia; é como se essa experiência fosse algo externo à vida, um excesso, com teor essencialmente negativo.

Mas ao olhar para a pessoa em suas possibilidades, incluindo os seus múltiplos contornos singulares, o que fica aparente não são patologias, mas as formas de ser em dado contexto, cercado de significados, expressões de sua humanidade. O sofrimento então, não seria algo extrínseco, mas parte constituinte desse ser, com a possibilidade de impulsionar mudanças significativas do sujeito e novas formas de ser.

Dessa forma, a medicalização pode ser vista como uma tentativa de desumanizar a vida humana, retirando também a autonomia e o contato da pessoa com seu próprio modo de ser na sua relação com o outro e o mundo. Em outras palavras, a patologização do cotidiano e a consequente medicalização, suprime a iniciativa a pessoa, o que acaba por gerar mais sofrimento. 


\section{REFERÊNCIAS}

Brzozowski, F. S., \& Caponi, S. N. C. de. (2013). Medicalização dos Desvios de Comportamento na Infância: Aspectos Positivos e Negativos. Psicologia: Ciência e Profissão, 33(1), 208-221. DOI: https://dx.doi.org/10.1590/S1414-98932013000100016

Buytendijk, F. J. J. (2018). A problemática da dor psicologia - fenomenologia - metafísica. Revista da Abordagem Gestáltica, 24(1), 101-113. DOI: https://dx.doi.org/10.18065/ RAG.2018v24n1.11

Canguilhem, G. (2009). O Normal e o Patológico. (6a ed.). Rio de Janeiro: Forense Universitária.

Christofari, A. C., Freitas C. R. de, \& Baptista, C. R. (2015). Medicalização dos Modos de Ser e de Aprender. Educação e Realidade, 40(4), 1079-1102. DOI: https://dx.doi. org/10.1590/2175-623642057

Faria, N. J. (2017). Noções de cuidado na atenção básica à saúde e Gestalt-terapia. In N. J. Faria, \& A. F. Holanda, Saúde Mental, Sofrimento e Cuidado. Curitiba: Juruá.

Foucault, M. (1988). Doença Mental e Psicologia. Rio de Janeiro: Tempo Brasileiro.

Frankl, V. E. (1946). Em busca de sentido (42a ed.). Petrópolis: Vozes.

Guarido, R. (2007). A medicalização do sofrimento psíquico: considerações sobre o discurso psiquiátrico e seus efeitos na Educação. Educação e Pesquisa, 33(1), 151-161. DOI: https://dx.doi.org/10.1590/S1517-97022007000100010.

Horwitz, A. V., \& Wakefield, J. C. (2009). The medicalization of sadness. Salute e Società, $8(2), 49-66$.

Illich, I. (1975). A expropriação da saúde: nêmesis da medicina (3a ed.). São Paulo: Nova Fronteira.

Lalande, A. (1938). Vocabularie technique et critique de la philosophie (2a ed.). Paris: Alcan.

Melo, A. K. da S., Ribeiro, J., \& Moreira, V. (2015). A Noção de Sofrimento: Possível Contribuição da Lente Fenomenológica dos Múltiplos Contornos. Revista de Psicologia, 6(1), 48-57. Recuperado de http://www.periodicos.ufc.br/psicologiaufc/article/view/1692

Merleau-Ponty, M. (1945/2011). Fenomenologia da Percepção. São Paulo: Martins Fontes.

Moysés, M. A. A., \& Collares, C. A. L. (2013). Controle e TESTE medicalização da infância. Desidades, 1(1), 11-21. Recuperado de http://pepsic.bvsalud.org/scielo.php?script=sci_ arttext\&pid=S2318-92822013000100002\&lng=pt\&tlng=pt

Ricoeur, P. (1991). O si mesmo como um outro. Campinas: Papirus.

Ricoeur, P. (1992). O sofrimento não é a dor. Paris: Revista Psychiatrie française.

Ricoeur, P. (1998). Interpretação e ideologia. Rio de Janeiro: Francisco Alves.

Scliar, M. (2007). História do Conceito de Saúde. Physis: Revista de Saúde Coletiva, 17(1), 2941. DOI: https://dx.doi.org/10.1590/S0103-73312007000100003 
Silva, J. C., Schäfer, C., \& Bonfiglio, M. S. (2013). A medicalização da infância e o processo psicoterápico. Barbaroi, (39), 70-86. Recuperado de http://pepsic.bvsalud.org/scielo. php?script=sci_arttext\&pid=S0104-65782013000200005\&lng=pt\&tlng=pt

Soalheiro, N. I., \& Mota, F. S. (2014). Medicalização da vida: doença, transtornos e saúde mental. Revista Polis e Psique, 4(2), 65-85. DOI: https://dx.doi.org/10.19131/rpesm.0132

Svandra, P. (2012). Douleur et souffrance, sur les pas de Paul Ricœur. Soins Psychiatrie, 33(282), p. 12-15.

Tabet, L. P., Martins V. C. S., Romano, A. C. L., Sá, N. M. de, \& Garrafa, V. (2017). Ivan Illich: da expropriação à desmedicalização da saúde. Saúde em Debate, Rio de Janeiro, 41(115), 1187-1198. DOI: https://dx.doi.org/10.1590/0103-1104201711516.

Teixeira, J. A. C. (2008). Psicologia da Saúde Crítica: Breve revisão e perspectiva existencialista. Análise Psicológica, Lisboa, 26(2), 335-345. Recuperado de http://www. scielo.mec.pt/scielo.php?script=sci_arttext\&pid=S0870-82312008000200013\&lng=pt\&t $\operatorname{lng}=\mathrm{pt}$

Tesser, C. D. (2006). Medicalização social (I): o excessivo sucesso do epistemicídio moderno na saúde. Interface - Comunicação, Saúde, Educação, 10(19), 61-76. DOI: https://dx.doi. org/10.1590/S1414-32832006000100005

Zanella, M., Luz, H. H. V., Benetti, I. C., \& Roberti Junior, J. P. (2016) Medicalização e saúde mental: Estratégias alternativas. Revista Portuguesa de Enfermagem de Saúde Mental, (15), 53-62. DOI: https://dx.doi.org/10.19131/rpesm.0132

Recebido em: 08-11-2019

Primeira decisão editorial: 03-12-2019

Aceito em: 11-12-2019 